\title{
A Survey on Effect of Smoking on Passive Smokers
}

\author{
Nimarpreet Kaur and Deepti Dwivedi \\ Department of Physiology Shree Guru Gobind Singh Tricentary \\ University, Gurugram, Haryana, India \\ Corresponding author email: nimarpreet_fmhs@sgtuniversity.org
}

\begin{abstract}
Second hand smokers are associated with serious health effects in non-smokers. The inhalation of harmful chemicals from second hand smoke affects passive smokers very seriously which ultimately leads to chronic respiratory related disorders and in worst condition demise. To analyze the effect of smoke on passive smokers a survey is conducted and is presented in the paper. The survey comprises of 250 participants who were further divided into four different groups. A questionnaire was provided to them comprising a bunch of questions and the response provided by them was collected and analyzed thoroughly. From the analysis it was observed that, all the groups were affected seriously by active smokers and group 2 and 3 are more surrounded by active smokers while group is least surrounded by active smokers but are facing serious health issues and also are more prone to chronic respiratory related disorders. Thus to conclude it is advised that it's better to stay away from smokers company and used N95 mask as they restricts the entry of $95 \%$ of harmful small sized particulates into respiratory tract thereby providing a heathy life to human beings.
\end{abstract}

\section{KEY WORDS: ACTIVE SMOKERS, PASSIVE SMOKERS, SMOKE, SURVEY.}

\section{INTRODUCTION}

Second hand Smoke (SHS) is a mixture of side stream smoke and mainstream smoke, exhalation of which is smoker's smoke. Cigarette smoke happens as SHS is inhaled by passive smokers, who ingest the same toxic compounds as smoker (E. M. Al-Sayed et. al. (2014)). SHS is a smoke that is inhaled by a passive smoker when exhaled by an active smoker. Although SHS was historically alluded to as ambient cigarette smoke, word second-hand smoke better understands the accidental significance of exposure. SHS remains in air until the end of cigarette products and may have harmful effects on the health, namely leukemia, respiratory problems and asthma, or even intensify these. The US Environmental Protection Agency classifies SHS as a 'documented cancer-induced human carcinogen'(J. E. Gotts (2017), C. Beadsmoore (2007).

Biosc Biotech Res Comm P-ISSN: 0974-6455 E-ISSN: 2321-4007

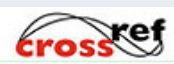

Identifiers and Pagination

Year: 2021 Vol: 14 No (6) Special Issue

Pages: $419-424$

This is an open access article under Creative

Commons License Attribn 4.0 Intl (CC-BY). DOI: $h t t p: / / d x$.doi.org/10.21786/bbrc/14.7.88
In the brief period, adults who are not smokers suffer from cigarette smoke mentally and get irritated. Breathing SHS instantly has adverse effects on cardiovascular system which can improve the heart disease risk. Persons with cardiovascular disease or allergies are highly vulnerable.(E. M. Al-Sayed (2014), M. Öberg (2011), T. A Merritt (2012)) Many studies have been conducted. Till date, limited studies over effects of passive smoking have been published. These analysis in addition, the research projects were not launched mainly Passive smoking involved. Consequently, some limits on the validity of these results would necessarily be made. The present paper focuses towards effects of active smokers on passive smoking.

Review Literature: Michale Kenter and colleagues have conducted a survey comprising 1351 collar workers to investigate how much passive inhalation of tobacco smoke affect bronchopulmonary function. A structured questionnaire presented information on active and passive cigarette smoke consumption. This caused the total category to be split into five subgroups: never smokers, passive smokers and ex-smokers, existing smokers, etc. Forced Expiratory vital capacity (FVC) and maximal expiratory flow -volume (MEFV) curves were involved for analyzing lung function. Passive smokers identified through this analysis represented no decline in parameters describing ventilatory function. It was concluded that, dose reliable

\section{Article Information}

Received: $15^{\text {th }}$ May 2021 ccepted after revision: $18^{\text {th }}$ July 2021 
and time reliable terms between active and passive smokers were determined(M. Kentner et. al. (1984). From the review it was observed that, though survey was conducted but none of the survey focused on sufferings of the person. Therefore in order to overcome the aforementioned drawback there is a need to conduct a survey comprising all the parameters required to analyze the effect of active smoking on passive smokers.

\section{Research Question}

1. What is the effect of active smokers on passive smokers?

2. Who is more prone to get infected with serious respiratory related disorders?

3. What are the preventive measure that one may take while being surrounded by active smokers?

\section{METHODOLOGY}

Design: In the survey conducted over effect of smoking on passive smokers involved 250 participants that were categorized into four groups on the basis of their age (Table 1). The participants preferred herein included both males and females. An enclosure was selected wherein all the participants were gathered. All the arrangements were done for the participants and special facilities were provided to participants falling in age category above 45 years. This was done so because old people may start feeling inactive which may affect their health and ultimately they may start losing interest in the survey. Before conducting the survey, a brief introduction about smoking and effects of smoking was provided to the participants. The session was conducted for 30 minutes which include what is smoking, what are the harmful effects of smoking, cases of death that took place within past one year, how it effects the second hand smokers and some of the rehabilitation centers that can be accessed if someone wants to quit smoking. Everything was presented to the participants on the projector. It was observed that the participants took interest in the session and gave a positive attitude towards it.

After the session, the questionnaire was provided to the respondents and the response generated by them was collected and analyzed strictly in order to avoid missing any parameter included in the questionnaire(D. M. Rosalin et. al. (2013)). The results were concluded and deep analysis was made regarding the health of the passive smokers and how much they get affected due to inhaling the smoke from the surroundings.

Table 1. Age category of participants

\begin{tabular}{|l|c|}
\hline GROUP & AGE \\
\hline GROUP 1 & $19-25$ YEARS \\
\hline GROUP 2 & $26-35$ YEARS \\
\hline GROUP 3 & $36-45$ YEARS \\
\hline GROUP 4 & $45-65$ YEARS \\
\hline
\end{tabular}

Sample: The survey comprises of the 250 members divided into four groups, wherein each group comprises of 50 members each. The members were provided questionnaire comprising 9 questions regarding the day to day activity of the passive smokers.

Instruments: The questionnaire comprised of nine questions. Each question was provided with sets of option, out of $\square$ which the participants has to choose one option (Table 2).

Data collection: The response was submitted by the respondents. The response sheets provided by them were collected successfully in order to analyze the data (Table 3-11).

\section{RESULTS AND DISCUSSION}

Which of the following people you consider smokers?: According to WHO, a smoker is a person who smokes tobacco, either daily or occasionally(R. Heshmat et. al. (2017)). When participants were asked about their perception on smokers most of them responded in accordance with the WHO. It was observed that, group 1, 2 and 3 completely agreed that any person who smokes daily or occasionally is a smoker while participants in group 4 have different opinion for that. $10 \%$ of the participants agreed that person who smokes while consuming alcohol is a smoker while $90 \%$ pf them responded in accordance with the WHO. The data analyzed indicates that the participants were aware of the smokers. They have a basic knowledge about smoking. However, participants in group 4 did not agree with this.

Are you surrounded by anyone who currently smokes?: Passive smoking is related with lower levels of anti-oxidants in the blood. This leads to thickening of the block which further blocks the arteries thereby leading to serious diseases such as cardiovascular diseases, stroke and alike(J. Saulyte et. al. (2014). Even though a person do not smoke but being in surroundings of smokers affect their health badly. Even chances of deterioration of there is more in comparison to smokers. Hence it is advisable to maintain distance with the smokers.

From the survey it was concluded that, all the groups i.e. group 1, group 2, group 3, and group 4 are surrounded by smokers at higher percentage. $70 \%$ of participants from group 1 were agreed that they are surrounded by smokers. Similarly, $90 \%$ of group 2 and group 3 and $75 \%$ of group 4 participants responded that they are surrounded by smokers who smoke currently. Data also revealed that some they were really not sure about the fact that they are surrounded by any kind of smokers. This certainly increases the chance of adversities in passive smokers. This happens because secondary smoking contains many harmful chemicals, so the smoke exhaled contains higher concentration of harmful chemicals as compared to smoke inhaled by the active smokers. The exhaled smoke inhaled by passive smokers strongly affects the coronary arteries of the passive smokers thereby leading to their adverse conditions.

Do you smoke presently?: Although the survey was conducted for passive smokers, but still they were asked about that if they consume smoke presently. The answer to 
this question was that, some of the participants in group 1, 2 , and 3 smoke occasionally i.e. once or twice a year. While group 4 participants did not smoke at all. This may be due to the age factor as old people are more to cardiovascular diseases as well as other respiratory related disorders. So they avoid from doing so. Smoking once or twice a year is not as dangerous as compared to active smokers or those who smoke occasionally. However, it is advisable to quit this habit as initial smokers may become active smokers very soon due to presence of nicotine, an agent present in the smoke that strongly affects the adrenaline of the brain and person gets attracted to it very much as it becomes very hard to quit it.

Table 2. Representation of questions asked in the questionnaire.

\begin{tabular}{|c|c|}
\hline S/No. & QUESTIONS \\
\hline 1. & $\begin{array}{l}\text { Which of the following people you consider smokers. } \\
\text { a) A person who smokes only when he is in } \\
\text { bublic. } \\
\text { b) A person who smokes while consuming } \\
\text { c) A person who only smoke after having meals. } \\
\text { d) A person who smokes regularly. } \\
\text { e) A person who smokes occasionally. } \\
\text { f) A person who smokes monthly. } \\
\text { g) All of the above. }\end{array}$ \\
\hline 2. & $\begin{array}{l}\text { Are you surrounded by anyone who currently smokes? } \\
\text { a) Yes } \\
\text { b) No } \\
\text { c) Not sure }\end{array}$ \\
\hline 3. & $\begin{array}{l}\text { Do you smoke at present? } \\
\text { a) Yes } \\
\text { b) No } \\
\text { c) Sometimes }\end{array}$ \\
\hline 4. & $\begin{array}{l}\text { When did you start smoking? } \\
\text { a) } 18-30 \text { years } \\
\text { b) } 31-45 \text { years } \\
\text { c) } 46-65 \text { years }\end{array}$ \\
\hline 5. & $\begin{array}{l}\text { Average hours per day you have seen or smelled smoke at } \\
\text { work. } \\
\text { a) } 2-5 \mathrm{hrs} \\
\text { b) } 6-10 \mathrm{hrs} \\
\text { c) } 10 \text { and above }\end{array}$ \\
\hline 6. & $\begin{array}{l}\text { How will you rate yourself in terms of activeness? } \\
\text { a) Very active } \\
\text { b) Active } \\
\text { c) Sedentary } \\
\text { d) Limited }\end{array}$ \\
\hline 7. & $\begin{array}{l}\text { Do you have any kind of medical history? } \\
\text { a) YES } \\
\text { b) NO }\end{array}$ \\
\hline 8. & $\begin{array}{l}\text { Have you experienced any kind or irritation in eyes, throat, or } \\
\text { alike in your surroundings? } \\
\text { a) Daily } \\
\text { b) More than once a week } \\
\text { c) More than once a month } \\
\text { d) Rarely/Never }\end{array}$ \\
\hline 9. & $\begin{array}{l}\text { Do you suffer from shortness of breath, if yes then how } \\
\text { frequently? } \\
\text { a) Regular activity } \\
\text { b) At night } \\
\text { c) While doing physical exercise }\end{array}$ \\
\hline
\end{tabular}

Table 3. Representation of response provided by respondents about whom they consider smokers.

\begin{tabular}{|l|c|c|c|c|c|c|c|}
\hline \multirow{2}{*}{ GROUPS } & \multicolumn{7}{|c|}{ OPTIONS } \\
\cline { 2 - 8 } & A) & B) & C) & D) & E) & F) & G) \\
\hline GROUP 1 & & & & & & & $100 \%$ \\
\hline GROUP 2 & & & & & & & $100 \%$ \\
\hline GROUP 3 & & & & & & & $100 \%$ \\
\hline GROUP 4 & & $10 \%$ & & & & & $90 \%$ \\
\hline
\end{tabular}

When did you start smoking?: $2 \%$ of group 1 participants agreed that they started smoking between 18-30 years and $3 \%$ responded that they started smoking between $31-45$
Table 4. Representation of response provided by respondents asking about who smokes currently.

\begin{tabular}{|l|c|c|c|}
\hline & YES & NO & NOT SURE \\
\hline GROUP 1 & $70 \%$ & $20 \%$ & $10 \%$ \\
\hline GROUP 2 & $90 \%$ & $5 \%$ & $5 \%$ \\
\hline GROUP 3 & $90 \%$ & $10 \%$ & $0 \%$ \\
\hline GROUP 4 & $75 \%$ & $25 \%$ & $3 \%$ \\
\hline
\end{tabular}

years. $4 \%$ of participants of group 4 responded that they started smoking between 18-30 years and 31-45 years of age. In group 3, 8\% of participants responded that they started smoking between 18-30 years of age while group 4 
completely disagreed from consuming cigarette. Average hours per day you have seen or smelled smoke at work.

Table 5. Representation of response provided by respondents asking do they smoke currently?

\begin{tabular}{|l|c|c|c|} 
& YES & NO & SOMETIMES \\
\hline GROUP 1 & $0 \%$ & $95 \%$ & $5 \%$ \\
\hline GROUP 2 & $0 \%$ & $90 \%$ & $8 \%$ \\
\hline GROUP 3 & $0 \%$ & $92 \%$ & $8 \%$ \\
\hline GROUP 4 & $0 \%$ & $100 \%$ & $0 \%$ \\
\hline
\end{tabular}

Table 6. Representation of response provided by respondents upon asking when did they start smoking?

\begin{tabular}{|c|c|c|c|} 
& $\mathbf{1 8 - 3 0}$ years & $\mathbf{3 1 - 4 5}$ years & $\mathbf{4 6 - 6 5}$ years \\
\hline GROUP 1 & $2 \%$ & $3 \%$ & - \\
\hline GROUP 2 & $4 \%$ & $4 \%$ & \\
\hline GROUP 3 & $8 \%$ & & \\
\hline GROUP 4 & $0 \%$ & $0 \%$ & $0 \%$ \\
\hline
\end{tabular}

Table 7. Representation of response provided by respondents upon asking about number of hrs they spent around people who smoke.

\begin{tabular}{|c|c|c|c|}
\hline & $\mathbf{2 - 5}$ hrs & $\mathbf{6 - 1 0}$ hrs & $\mathbf{1 0}$ and above \\
\hline GROUP 1 & $60 \%$ & $90 \%$ & $5 \%$ \\
\hline GROUP 2 & $30 \%$ & $90 \%$ & $15 \%$ \\
\hline GROUP 3 & $60 \%$ & $90 \%$ & $5 \%$ \\
\hline GROUP 4 & $85 \%$ & $5 \%$ & $5 \%$ \\
\hline
\end{tabular}

Table 8. Representation of response provided by respondents upon asking about rating themselves in terms of activeness.

\begin{tabular}{|l|c|c|c|}
\hline & Very active & Active & Sedentary Limited \\
\hline GROUP 1 & $80 \%$ & $15 \%$ & $5 \% 0 \%$ \\
\hline GROUP 2 & $75 \%$ & $15 \%$ & $10 \% \mathbf{2 \%}$ \\
\hline GROUP 3 & $50 \%$ & $65 \%$ & $25 \% 10 \%$ \\
\hline GROUP 4 & $15 \%$ & $20 \%$ & $50 \% 35 \%$ \\
\hline
\end{tabular}

Table 9: Representation of response provided by respondents upon asking about their medical history.

\begin{tabular}{|l|l|l|}
\hline & YES & NO \\
GROUP 1 & $\checkmark$ & $\mathbf{x}$ \\
\hline GROUP 2 & $\checkmark$ & $\mathbf{x}$ \\
\hline GROUP 3 & $\checkmark$ & $\mathbf{x}$ \\
\hline GROUP 4 & $\checkmark$ & $\mathbf{x}$ \\
\hline
\end{tabular}

Table 10. Representation of response provided by respondents upon asking if they have experienced any kind or irritation in eyes, throat, or alike in your surroundings.

\begin{tabular}{|l|c|c|c|c|}
\hline & Daily & $\begin{array}{r}\text { More } \\
\text { than once } \\
\text { a week }\end{array}$ & $\begin{array}{c}\text { More } \\
\text { than once } \\
\text { a month }\end{array}$ & $\begin{array}{c}\text { Rarely/ } \\
\text { Never }\end{array}$ \\
\hline GROUP 1 & $90 \%$ & $10 \%$ & $0 \%$ & $0 \%$ \\
\hline GROUP 2 & $95 \%$ & $5 \%$ & $0 \%$ & $0 \%$ \\
\hline GROUP 3 & $85 \%$ & $10 \%$ & $0 \%$ & $0 \%$ \\
\hline GROUP 4 & $60 \%$ & $20 \%$ & $10 \%$ & $0 \%$ \\
\hline
\end{tabular}

Table 11. Representation of response provided by respondents upon asking if they suffer from shortness of breath, if yes then how frequently.

\begin{tabular}{|c|c|c|c|c|}
\hline & $\begin{array}{c}\text { YES } \\
\text { Regular } \\
\text { activity }\end{array}$ & $\begin{array}{c}\text { At } \\
\text { night }\end{array}$ & $\begin{array}{c}\text { While } \\
\text { doing physical } \\
\text { exercise }\end{array}$ & NO \\
\hline GROUP 1 & $75 \%$ & $5 \%$ & $20 \%$ & - \\
\hline GROUP 2 & $85 \%$ & $10 \%$ & $30 \%$ & - \\
\hline GROUP 3 & $80 \%$ & $15 \%$ & $10 \%$ & - \\
\hline GROUP 4 & $30 \%$ & $70 \%$ & $5 \%$ & - \\
\hline
\end{tabular}

The answer to this question varied from people to people. $30 \%$ of participants from group 1 inhale the second hand smoke for about 2-5 hrs while $90 \%$ of them inhale for 6-10 hrs and $5 \%$ of them inhale for 10 hrs and above. Similarly, group $30 \%, 60 \%$ and $85 \%$ of participants from group 2,3 and 4 respectively inhale second hand smoke for a duration of $2-5 \mathrm{hrs} .90 \%$ of participants from group 1, 2 and 3 inhale second hand smoke for $6-10 \mathrm{hrs}$ and $5 \%$ of participants of group 4 inhale the same for 6-10 hrs. Percentage for group $1-4$ ranged from $5 \%-15 \%$ (5\% for group 1, 3 and 4 and $15 \%$ for group 2 ).

From the data it was analyzed that, $90 \%$ of the participants from group 1, 2 and 3 are highly affected from smoke between 6-10 hrs. The reason behind this is that the age group ranging from 19-45 years comprises of students or employees. The working hrs of the office and colleges are also around 6-10 hrs. Thus this is the high time of exposure to second hand smoke as hanging out with colleagues and friends during non-working hrs make some of them to smoke which directly influence the passive smokers. Thus passive smokers come under high risk zone during this time. People belonging to group 4 fall in age category of 46-65 years. This age group mostly reside indoors and do not come in direct contact with the active smokers. However, due to age line their minimum exposure with active smokers makes them prone to respiratory related disorders due to weak immune system of the group. Thus it is highly advisable to maintain distance from active smokers, specifically group 4 participants. 
How will you rate yourself in terms of activeness?: From the data it was analyzed that, $80 \%$ of participants from group 1 were very active followed by $75 \%$ from group 2 , $50 \%$ from group 3 and $15 \%$ from group 4 . Due to strong immune system of the participants lying in group 1 are very active. It can be concluded that even though participants in group 1 are very active while inhaling second hand smoke but it should not be neglected that their immune system is affecting day by day. After achieving the saturation point their lungs can be affected adversely. Also if situation gets worse than chances of recovery are more in participants belonging to group 1 and 2. But group 3 and 4 are at high risk when get exposed to second hand smoke.

Do you have any kind of medical history?: It is important to know about medical history of the passive smokers as it will aid in analyzing the level of risk of the participants( $R$. Bonita (1999), J. Christie (2013). From the data it is analyzed that, all the groups were had medical history. From the survey it was observed that, group 1 were mostly suffering from sleep apnea, asthma, ear infection and sinus problem. Participants belonging to group 2 were suffering from Asthma, thyroid, diabetes, and sinus problem. Group 3 were suffering from high blood pressure, diabetes, lung cancer, breast cancer, chronic bronchitis and group 4 were suffering from Coronary Angioplasty or stent, lung cancer, Heart bypass surgery, congestive heart failure and high blood pressure. From the above data it is analyzed that, each of the group is suffering from one or the other problems which is a matter of concern. The main reason for all these suffering is high pollution, slower metabolism and inappropriate diet. Also being surrounded by active smokers enhance the symptoms and thus make them prone to serious conditions which in future may also lead to their demise.

Have you experienced any kind or irritation in eyes, throat, or alike in your surroundings?: The answer to this question was "yes" from all the participants. All the groups face irritation in eyes, throat etc. The percentage ranged from $60 \%-95 \%$. Group 2 with $95 \%$ face maximum problem. This may be due to the fact that, that group is mostly involved in work profiles and thus are much exposed to passive smoking by having direct contact with their employers, friends and alike. Secondly, $90 \%$ of participants from group 1 face difficulty in their eyes and throat followed by group $3(85 \%)$ and group $4(60 \%)$.

Do you suffer from shortness of breath, if yes then how frequently?: $75 \%$ participants of group 1 suffered from shortness of breath while performing regular activity, followed by group $2(85 \%)$, group $3(80 \%)$, group $4(30 \%)$. Similarly, 5\% participants of group 1 suffered breath shortness followed by group $2(10 \%)$, group $3(15 \%)$, group $4(70 \%)$. While doing physical exercise, $20 \%$ of group 1 members suffered shortness of breath followed by $30 \%$ of group 2, group $3(10 \%)$, and group 4 (5\%). From this it can be concluded that, harmful chemicals from second hand smoke block the arteries by thickening the blood and thus creates problem in expansion and contraction of lungs. This leads to shortening of breath. The person most affected from this belongs to group 4. As due to their age factor, week immunity their arteries constrict and thus creates problems in breathing. That is why they are more prone to coronary artery diseases, stroke, and heart attack and alike.

\section{CONCLUSION}

Due to passive smoking there exist increased consequences of sinus, throat carcinoma, larynx carcinoma, breast carcinoma along with long and short duration respiratory symptoms, pulmonary related disorders in those people who do not smoke. The present survey, focused on effect of smoke on passive smoking. From the survey conducted it was observed that, harmful chemicals produced from the smoke exhaled form active smokers directly attacks the respiratory tract of the non-smokers. This leads to the development of the chronic diseases among them. It was also observed that, participants from group 1 belong to age category 19-25 years. They are more exposed to smokers and are more affected by the harmful particulates from the smoke. However, due to strong immune system they sometimes bear that attack from the harmful chemicals but as the duration passes, their health start deteriorating and become worse at certain point of time. Similar is the case with group 2 and 3.

Group 2 and 3 comprises of persons belonging to age group 26-35 years and 36-45 years respectively. These group members mostly include member who are working. They being surrounded by their colleagues most of which smokes a lot. On an average a smoker can smoke more than 17 cigarettes in one and being surrounded by them affects the health of the non-smokers very badly. From the survey, it was noted that they are also being surrounded by the active smokers although they are affected but due to strong immune system at this age protects them from serious side effects. Group 4 participants belong to age group 4665 years. This group is more prone to chronic respiratory related disorders. This is due to their weak immunity. Thus it is recommended that the older group should maintain strict distance from the active smokers and thus practice yoga and meditation to live a healthy life. Moreover, wearing N95 mask when surrounded by active smokers is highly recommendable as it prevents the entry of particulates into the respiratory tract of the person.

\section{REFERENCES}

Al-Sayed, E.M. and Ibrahim, K.S., 2014. Second-hand tobacco smoke and children. Toxicology and industrial health, 30(7), pp.635-644.

Beadsmoore, C., Cheow, H.K., Szczepura, K., Ruparelia, P. and Peters, A.M., 2007. Healthy passive cigarette smokers have increased pulmonary alveolar permeability. Nuclear medicine communications, 28(2), pp.75-77.

Bonita, R., Duncan, J., Truelsen, T., Jackson, R.T. and Beaglehole, R., 1999. Passive smoking as well as active smoking increases the risk of acute stroke. Tobacco control, 8(2), pp.156-160.

Callinan, J.E., Clarke, A., Doherty, K. and Kelleher, C., 2010. Legislative smoking bans for reducing secondhand smoke exposure, smoking prevalence and tobacco 
consumption. Cochrane database of systematic reviews, (4).

Gotts, J.E., Abbott, J., Fang, X., Yanagisawa, H., Takasaka, N., Nishimura, S.L., Calfee, C.S. and Matthay, M.A., 2017. Cigarette smoke exposure worsens endotoxin-induced lung injury and pulmonary edema in mice. Nicotine \& Tobacco Research, 19(9), pp.1033-1039.

Heshmat, R., Qorbani, M., Safiri, S., Babaki, A.E.S., Matin, N., Motamed-Gorji, N., Motlagh, M.E., Djalalinia, S., Ardalan, G., Mansourian, M. and Asayesh, H., 2017. Association of passive and active smoking with selfrated health and life satisfaction in Iranian children and adolescents: the CASPIAN IV study. BMJ open, 7(2), p.e012694.

Kentner, M., Triebig, G. and Weltle, D., 1984. The influence of passive smoking on pulmonary function-a study of 1,351 office workers. Preventive medicine, 13(6), pp.656-669.

Merritt, T.A., Mazela, J., Adamczak, A. and Merritt, T., 2012. The impact of second-hand tobacco smoke exposure on pregnancy outcomes, infant health, and the threat of third-hand smoke exposure to our environment and to our children. Przeglad lekarski, 69(10), pp.717-720.

Saulyte, J., Regueira, C., Montes-Martínez, A., Khudyakov, P. and Takkouche, B., 2014. Active or passive exposure to tobacco smoking and allergic rhinitis, allergic dermatitis, and food allergy in adults and children: a systematic review and meta-analysis. PLoS medicine, 11(3), p.e1001611.

Somantri, U.W., 2020. HUBUNGAN TINGKAT PENGETAHUAN, JENIS KELAMIN DAN PERSEPSI GAMBAR KEMASAN ROKOK DENGAN PERILAKU MEROKOK. Jurnal Kesehatan, 11(1), pp.69-76.

Wipfli, H.L. and Samet, J.M., 2010. Second-hand smoke's worldwide disease toll. Lancet (London, England), 377(9760), pp.101-102. 